\title{
Artigo
}

Infâncias públicas. Não é justo é o título do livro que publicaremos em breve e no qual exporemos o desenvolvimento de uma investigação psicanalítica que não seguiu os caminhos habituais. O discurso da "menoridade" é analisado como a outra face da Infância Moderna. Psicanálise;infância; menoridade

PUBLIC INFANCY. THERE IS NO JUSTICE

Public infancy. There is not justice is the book's headline that will be soon published and in which we will expose the development of an unusual psychoanalytic research. The "minority" discourse is analyzed as another face of the notion of Modern Infancy.

Psychoanalysis; infancy; minority

\section{INFÂNCIAS \\ PÚBLICAS. NÃO É JUSTO}

\author{
Mercedes Minnicelli \\ Tradução: Daniela Teperman
}

$\underline{I}$

- Infâncias públicas. Não é justo é o título do livro que publicaremos em breve e no qual exporemos o desenvolvimento de uma investigação que não seguiu os caminhos habituais.

O nome foi posto só quando finalizado o trabalho. "Caiu" como uma síntese ou conclusão que possibilita novas vias de tratamento do tema cujo percurso foi o de um caminho sinuoso para o qual foram convergindo diversos caminhos de formação e experiências: a prática e formação clínica psicanalítica; a gestão pública; as questões que a partir de um e do outro lado foram sendo formuladas, na tentativa de tornar-se discurso e dar lugar à palavra.

No que diz respeito à psicanálise nas instituições, esta pesquisa começa formalmente em 1994 no Grupo de Investigação Teoria e Práticas Psicanalíticas da Faculdade de Psicologia da Universidade Nacional de Mar del Plata (UNMDP), problematizando a subjetividade daquele que ensina e as relações de ensino.

A investigação no concernente "às instituições de menoridade" começa em 1997, momento no qual

- Psicanalista, doutora em Psicologia pela Faculdade de Psicologia da Universidade Nacional de Rosario, professora na Faculdade de Psicologia da Universidade Nacional de Mar del Plata, ex-diretora da Infância do município de General Pueyrredón, na Argentina. 
a autora deste trabalho foi convocada a exercer uma função pública, tendo sido encarregada da Direção da Infância no município de General Pueyrredón.

A convocação a exercer a função pública tornava-me uma "estrangeira" em relação à "tradição" em menoridade, dada minha trajetória em clínica psicanalítica, em instituições educativas e na investigação psicanalítica universitária.

Essa foi uma escolha da gestão da Secretaria de Qualidade de Vida daquele município, na tentativa de reestruturar a área e "abrir" as instituições e seu discurso, em direção às diretrizes da Convenção Internacional dos Direitos da Criança.

A partir desse momento, começou, de maneira simultânea à gestão, a coleta de material que pudesse servir e nutrir uma investigação posterior, uma vez finalizada a tarefa. $\mathrm{O}$ tempo de exercício da gestão institucional foi de dois anos, de dezembro de 1997 a dezembro de 1999.

A pesquisa universitária foi realizada de fevereiro de 2000 até janeiro de 2003, no Grupo de Investigação Sociologia dos Vínculos entre Universidade e Comunidade, da Faculdade de Psicologia da UNMDP.

A denominação do projeto em sua primeira parte foi "Práticas sociais cotidianas legitimadoras do discurso de menoridade: Efeitos na constituição subjetiva de crianças sob tutela judicial".

A segunda parte foi denominada "Infância, direitos da criança e psicanálise: Factibilidade de aplicação da Convenção Internacional dos Direitos da Criança no enquadre de práticas de criação familiares e institucionais".

Em todos os casos, os projetos foram financiados mediante bolsas de investigação obtidas por concurso nas sucessivas categorias que a UNMDP concede.

A apresentação que fazemos nesse livro não conserva exprofesso os aspectos formais de um "relatório final".

Interessou-nos incluir as perguntas iniciais e o devir de hipóteses que fomos gestando a partir da análise de casos e intervenções, pretendendo analisar também seus efeitos, seus obstáculos, seus sentidos e "sem-sentidos".

A possibilidade de chegar às hipóteses que formulamos e à habilitação das vias de análises que propomos é produto da investigação bibliográfica e da análise dos dados obtidos de diversas fontes e com diferentes técnicas: este é o caso da pesquisa sobre a relevância da capacitação do pessoal; a análise de prontuários judiciais e expedientes administrativos; de relatórios de psicólogos, trabalhadores sociais, terapeutas ocupacionais, professores e psicopedagogos; de cadernos de classe das crianças; de cadernos de co- 
municações escolares; entrevistas com pessoal da área; cadernos de comunicação interna do pessoal; atas de reuniões; livros de atas institucionais; relatórios realizados; reconstrução de intervenções realizadas, nas quais foram participando diversas dependências e instituições (cujos relatórios constam nos expedientes municipais); análises de regulamentações vigentes; relatos de experiências; observações ocasionais. Nestes dois últimos casos, estes dados foram recolhidos às vezes de maneira informal, motivo pelo qual costumam ser excluídos das investigações, e é justamente ali que encontramos muitas vezes maior riqueza de informações para a análise do problema.

Digamos que todos os dados coletados foram considerados a posteriori e tratados como um texto oferecido à análise, e se encontram todos devidamente registrados.

Ainda que o ponto de partida teórico-clínico seja a psicanálise, a investigação teórica ocorreu a partir de um ir-e-vir permanente a outras disciplinas, estendendo o horizonte de análise do problema que nos ocupa, sabendo que podemos cometer certos erros que atentam contra as bases epistemológicas oficiais, ao considerar recortes no que diz respeito a desenvolvimentos mais amplos ou mais específicos - como no caso da seleção de alguns autores, e não outros.

O rastreamento bibliográfico foi especificado na bibliografia de referência.

Pensamos que o tratamento do tema o exige e que é necessário ultrapassar - com o risco de transgredir - as barreiras epistemológicas disciplinares, mas sendo fiéis à significação que cada discurso confere a seus conceitos.

Apelar à história permite-nos detectar o tempo e o lugar em que fincam suas raízes o Complexo Tutelar e suas Instituições, em que foi gestado um determinado discurso e saberes hegemônicos, no que diz respeito aos "menores". Produção moderna por excelência, que é um divisor de águas no imaginário a respeito das crianças. Umas serão "crianças" e outras serão "menores".

Este livro procura ser um disparador para alimentar o debate interdisciplinar e leigo. Procura começar a desemaranhar a meada que aprisiona subjetividades. Procura des-cobrir que o inexorável de um intrincado labirinto não são mais que circuitos de intercâmbios legitimadores sobre os quais é possível operar a fim de que os pequenos não sejam objeto de gozo adulto. Que o tentemos não quer dizer que consigamos, já que apenas começamos a entrar na questão de por que é tão complexo e é tanta a resistência para dar lugar à criança e seus direitos; e por que é tão difícil a abordagem clínica com crianças que não foram tratadas como tais. 
Tomando esse ponto como referência é que, partindo do fazer e da ética da psicanálise e sem desviarnos desse rumo, adentramo-nos nos estudos historiográficos que nos pareceu relevante situar como primeira parte deste texto.

A pergunta a respeito da tolerância daquelas situações que poderíamos qualificar como infanticídio nos faz presente uma e outra vez.

A pergunta a respeito da implacável associação menoridade-delinqüência e a marca provocada por essas denominações encontram seus antecedentes na história e se atualizam no presente em uma repetição incansável e fatal, apresentando-se em muitíssimas ocasiões na forma do sinistro.

As transformações em relação ao sentimento de infância. A família "oficial" e as formas familiares. O complexo tutelar. As instituições. No Antigo Regime, as amas-de-leite. No mundo moderno, as instituições de menores. Em nosso tempo, a defesa dos direitos da criança a deixa à deriva? É uma utopia?

Levantar questões na história permite-nos desmistificar diversas idéias arraigadas na forma de preconceito e sentença. Sem mais inexorável destino. História de um presente que aparece como incompreensível nas formas que as infâncias e adolescências de muitas crianças hoje se apresentam e da qual são produto impensado e impensável.

Escutá-los não é tarefa fácil. O que têm para dizer nos interpela. Escutá-los é o primeiro passo a seguir, se é que desejamos fazer algo em conjunto com eles, e não, exclusiva- 
mente, para eles. Dar a palavra às crianças a fim de possibilitar espaços de intercâmbio e diálogo com elas faz explodir as instituições. Dar lugar à palavra das crianças nos compromete.

Iremos compartilhando o percurso realizado, incluímos as reflexões que foram se apresentando, as dúvidas; as questões que a análise promoveu, e algumas conclusões que não fazem mais que abrir novas vias de investigação, pretendendo des-cobrir este sistema organizado expressamente como "labirinto".

E chegamos à metáfora do "labirinto" e dela nos servimos ao longo do trabalho, quando não pudemos encontrar melhor maneira de nomear o modo pelo qual o próprio discurso de menoridade gera, em todas e em cada uma de suas ações, por um lado, a ilusão de "estar fazendo tanto por eles!!!!” e, por outro lado e ao mesmo tempo, o encerramento e a obturação das condições e oportunidades de subjetivação que merecem todas e cada uma das crianças que por motivos de diversa índole requerem a intervenção direta do Terceiro social da palavra (Legendre), representado pelo Poder Judicial - enquanto veículo da lei - e as organizações institucionais.

Chamaremos "becos do labirinto" os circuitos de intercâmbio legitimadores (Bourdieu).

Somente entrando e saindo dos e pelos "becos do labirinto" será possível encontrar aqueles pontos nos quais é necessária a habilitação da circulação entre os "becos" desconectados entre si. As barreiras a derrubar são múltiplas.
No entanto, será factível que entre alguma luz ante tanto silenciamento e ocultamento que a própria estrutura do Estado propiciou, se realmente se deseja dar outro lugar e, um lugar Outro, às novas gerações de tantas crianças que, hoje, parece que não encontram - sabiamente, em muitos casos - melhor lugar para viver que a rua, no paradoxo que representa a ilusão de liberdade que buscam, o desamparo que escondem ao representar a outra face de uma mesma moeda: a infância moderna.

II. Seguindo o texto freudiano, aquilo que denominamos "laços sociais" refere-se a "laços libidinais ou múltiplas ligações de identificação" (Freud, 1921), que possibilitam a inscrição do infantil sujeito no universo simbólico, filiando-o a uma linhagem, a uma tradição, tornando factível sua constituição e inscrição como sujeito de sua cultura, sujeito da linguagem.

Uma pergunta que trabalharemos é a seguinte: em tempos de infância, em tempos de constituição subjetiva, que efeitos são produzidos quando o universo simbólico é transmitido à criança por um sistema alheio ao propriamente familiar; quando um infante ingressa ao próprio e particular universo lingüístico do discurso de menoridade?

Quando intervém um tribunal de menores, é iniciada uma "causa judicial" em que constarão as sucessivas intervenções de diversos agentes fixando os "antecedentes" em um prontuário ou expediente. Nesse ato jurídico-administrativo, a criança ingressa no Sistema de Menoridade. Considerando esta ação como um ato de afiliação, por sua vez, as suas práticas, valores, consensos se- 
rão significativamente similares aos que também pertencem ao léxico e códigos carcerários, podendo produąir-se a passagem da afiliação à filiação imaginária à linhagem da menoridade, selando uma cadeia genealógica fracassada que se apresenta como inexorável.

A filiação a uma "causa judicial' inicia uma singular diferença em relação a outras crianças: a identidade desse sujeito passará a ser pública (Goffman, 1961). Incorporará - paulatina e sucessivamente - traços, nomeações, marcas identificatórias próprias desse Sistema e de seu Discurso, favorecendo um verdadeiro curto-circuito psíquico em relação à genealogia familiar sem poder de operar enquanto legalidade ordenadora, situando a criança como objeto de gozo de um sistema que necessita dela e a retém nesse lugar para subsistir.

Muitas vezes a criança deseja escapar é, justamente, dos abusos dos quais é objeto no próprio enredo de laços familiares de origem. Apela então a outro lugar. E se encontra com mais do mesmo.

A ausência de legalidade que instaure uma diferença substantiva entre o permitido e o proibido no familiar e no social é evidente.

A essas crianças é oferecida a "satisfação de necessidades básicas" em troca da entrega de sua vida até atingir a maioridade, quando o fato de estas estarem na instituição responde na maior parte dos casos a delitos não cometidos por elas; cujos atores, salvo honrosas exceções, não contam com a sanção social que as próprias crianças pedem aos gritos.

É patético o caso de crianças vítimas de abuso e/ou violação que foram e são "internadas" até atingir a maioridade, enquanto os autores adultos desses delitos continuam livres de culpa e acusação.

Seguindo o texto freudiano, Marta Gerez Ambertín enuncia "quando os verdugos não se responsabilizam por sua falta, a culpabilidade recai para o lado das vítimas", ou, dito de outro modo, "quando os pais não se responsabilizam por sua falta, sobram os filhos para carregar a culpa".

Os motivos que dão origem à intervenção judicial são múltiplos, como múltiplas também são as causas de internação. Nesse ato mediante um ofício judicial, os juízes de menores delegam (sob a figura legal da guarda) ${ }^{1}$ a responsabilidade da internação a instituições públicas (nacionais, provinciais, municipais, até mesmo ONGs).

No entanto, a criança "depende do juiz" a partir desse momento.

Dependendo também de que juiz se trate, serão as decisões que recairão sobre a criança. $\mathrm{O}$ poder discricionário do juiz é aplicado em todos e em cada um dos casos. Alguns com resolução 
mais favorável que outros, quando de subjetividade e legalidade se trata.

Dupla dependência, já que as instituições, sejam estas municipais, provinciais ou nacionais, não dependem do poder judicial, mas do poder administrativo (executivo). Ainda que as crianças "tuteladas" dependam. A responsabilidade que recai sobre as organizações institucionais sob a figura da "guarda" merece ser considerada. Curto-circuito que se expressa na disjunção existente entre o que acontece "dentro" das instituições e a "proteção" que nelas se pretende.

A resolução da questão não é simples, e não será um propósito deste livro apresentá-la. Mas sim é de nosso interesse possibilitar, a partir deste texto, novas vias de análise que nos permitam compreender a economia labiríntica do sistema, ao tornar visíveis seus pontos mais obscuros.

Que fenômeno provoca tanta dificuldade para promover mudanças no sistema de menoridade? Dar outro lugar às crianças é uma utopia? Um espelhismo? Uma ilusão de ótica?

Ainda que o atual contexto, que oferece a mudança legislativa que atualmente está tramitando ${ }^{2}$, promova reformas nos regulamentos institucionais e em seus critérios organizacionais, em razão da análise destas resistências, consideramos que foi pouco considerada a marca histórica que instituiu o próprio Discurso de Menoridade e se legitima nas práticas cotidianas reguladoras das relações que são estabelecidas tanto entre adultos (representantes judiciais, profissionais, funcionários, diretores, meios de comunicação, monitores, precep- 
tores, operadores, pais substitutos, etc.) e crianças deprivadas ${ }^{3}$, como, reciprocamente, entre as próprias crianças e suas famílias (Winnicott, 1940).

Uma legalidade parece estar indefinida, a proibição do incesto e a operação subjetiva que esta possibilita. Sem interdição, sem legalidade familiar e social que ordene o desvario pulsional, próprio à infância, as relações se traduzem em um imaginário no qual não há sanção nem distinção entre o permitido e o proibido. Apenas atos, poucas palavras. Apesar disso, de um modo ou outro, a essa interdição apelam.

Propusemo-nos a questionar os modos pelos quais cada uma das práticas sociais cotidianas ${ }^{4}$ levadas a cabo com e pelos agentes de intervenção direta ${ }^{5}$ (Bourdieu) imprime no frágil psiquismo infantil marcas, traços, que o identificam ao discurso de menoridade ${ }^{6}$ e o desconhecem em sua infância.

Os intercâmbios discursivos entre crianças e adultos ativam complexos interjogos psíquicos de identificações e transferências ficando sujeitos - ambos - a estabelecer a relação de acordo com suas respectivas e singulares histórias infantis (Minnicelli, 1997).

De fato, é substantiva a influência dessas relações como legitimadoras do Discurso de Menoridade por meio das práticas que significam dia a dia a experiência de infantes e adolescentes que, de forma transitória ou permanente, são "criados" (mais que favorecida sua subjetivação) por representantes do Estado.

E é possível brincar com a significação que em espanhol tem a palavra "criado" em sua associação significante com a "escravidão" na história de nosso país, assim como de outros da América Latina. A cada tentativa de ganhar "liberdade", mais presas ficam as crianças a esse lugar de "escravidão".

E são "escravas" de sua história, que apresenta sérias dificuldades de ser historicizada.

E são "escravas" de outra história, a história do sistema.

Para sustentar essa hipótese, exporemos aquelas práticas que se mostram e se ocultam no espaço de autonomia (Gutiérrez, 1995, p. 33) e decisão que o adulto conserva sobre a criança.

No entanto, essas práticas não são próprias de nosso tempo exclusivamente, tal como o demonstram os estudos historiográficos que analisaremos na primeira parte. O que chama a atenção é que, enquanto discurso, conserve-se praticamente intacto, apesar das tentativas de mudança de critérios e de mudanças no contexto de produção próprio a nossos tempos, que nos diferenciam do Antigo Regime. As crianças foram objeto de atrocidades, com maior ou menor legitimidade, com maior ou menor consciência disso, ao longo da história. O que nos surpreende é, justamente, 
que sejam oferecidas em sacrifício enquanto geração em advento. O sacrifício é subjetivo e transcende sem rupturas, repetindo-se geração após geração.

O discurso de menoridade, ao enunciar menor para nomear uma criança, consegue outorgar caráter de natural e necessário ao que nos atrevemos a denominar ficções próprias de um discurso, reconhecidas como tais quando se possibilitam a interrogação e a reflexão sobre a "conservação" de certas normas, tradições, economias, jogos de relações, instituindo um discurso sem revisão que determina o trato e o tratamento ${ }^{8}$ daquelas crianças "beneficiárias" da atenção do Estado.

Não partiremos do presente, mas faremos presente a história. O convite é a deslocarmo-nos aos tempos do Antigo Regime e às transformações que operam em Tempos Modernos Ocidentais. Passaremos pela Europa percorrendo os estudos historiográficos de Philippe Ariès e Jacques Donzelot, chegando logo à América Latina em tempos de emancipação colonial, pontuando os trabalhos realizados por Ricardo Cicerchia. A partir de lá chegaremos à Argentina dos séculos XIX e XX, para chegar à costa marplatense, detendo-nos no município de General Pueyrredón, na província de Buenos Aires, República Argentina, com a análise dos dados de uma pesquisa reveladora dos critérios que sustentam as decisões que, em relação ao pessoal encarregado das crianças, o Estado, em nível municipal, vem sustentando.

Aspecto a interrogar, já que partimos da base que maior capacitação formal não implica disponibilidade para assumir a responsabilidade pela educação de uma criança. Sim, interessa-nos destacar, como o próprio sistema garante a inviabilidade de circulação de capital cultural, simbólico, outorgando desse modo um lugar no presente e, lamentavelmente, no futuro dessas novas gerações. Um lugar sem história. Um lugar sem ressignificação do passado. Um lugar em que a única alternativa viável que se apresenta para a criança é, na maioria dos casos, achar estratégias de sobrevivência no aqui e agora de cada dia. 


\section{Artigo}

\section{REFERÊNCIAS BIBLIOGRÁFICAS}

Freud, S. (1921). Psicología de las masas y análisis del yo, Cap. "La identificación”. In Obras completas (Tomo XVIII).

Goffman, E. (1961). Internados. Ensayos sobre la situación social de los enfermos mentales. Buenos Aires: Amorrortu, 1984.

Gutiérrez, A. (1995). Pierre Bourdieu. Las prácticas sociales. Posadas: Editora Universidad Nacional de Misiones.

Minnicelli, M. (1997). Estudios psicoanalíticos en la universidad, Cap. 4, "Relación de enseñanza, relación de influencias". Homo Sapiens.

Winnicott, D. (1940). El niño y el mundo externo. Buenos Aires: Hormé, $3^{a}$ ed., 1986.

\section{NOTAS}

${ }^{1}$ Lei Provincial do Patronato do Menor (Buenos Aires) no 10067.

2 Convenção Internacional dos Direitos da Criança. Ratificada pela Lei do Congresso n 23849 e incorporada ao texto da Constituição Nacional em 1994, coexistindo com a Lei Provincial no 10067 e a Lei Nacional no 10903.

3 A palavra "deprivada" deve ser entendida como privada do afeto e contato com seus filhos. $\mathrm{O}$ inverso seria a criança privada de afeto e contato com sua mãe $(\mathbb{N}$. do T.).

4 Abre-se outra via de investigação se consideramos como objeto os motivos pelos quais se decide que uma criança entre em uma instituição de menores.

5 Juízes, funcionários de tribunais, diretores, preceptores, operadores ou cuidadores, profissionais, educadores, etc.

6 Ver Parte II.

7 Tem a mesma significação que na língua portuguesa (N. do T.).

${ }^{8} \mathrm{O}$ estudo de relatórios profissionais (psicológicos, sociais, etc.) evidencia também o que aqui é apresentado. 